\title{
APLICAÇÃO FOLIAR DE SILÍCIO EM PLANTAS DE TRIGO ASSOCIADO A QUALIDADE FISIOLÓGICA DE SEMENTES
}

\author{
Sergio Gonçalves de Oliveira Júnior ${ }^{1}$, Evander Alves Ferreira ${ }^{1}$, Marcela Carlota Nery ${ }^{1}$, Ramon \\ Francisco Cordeiro Silva ${ }^{1}$, Soryana Gonçalves Ferreira de Melo ${ }^{1}$, Cíntia Maria Teixeira Fialho ${ }^{1 *}$
}

\begin{abstract}
RESUMO - Na busca de sementes e plantas de alto padrão de qualidade, a utilização do silício pode ser interessante na agricultura, pois pode incrementar a produtividade, regular a perda de água, melhorar a taxa fotossintética, aumentar a rigidez da estrutura dos tecidos entre outros. Dessa forma, objetivou-se com essa pesquisa verificar o efeito da aplicação foliar de silício no crescimento, fisiologia de plantas de trigo e na qualidade de sementes de trigo produzidas. Empregou-se o delineamento experimental em blocos casualizados com fatorial $2 \times 4$ com 5 repetições, onde os tratamentos foram compostos por duas cultivares de trigo (BR18 e BRS254) e quatro dosagens da formulação comercial Supa Sílica da marca Agrichem ${ }^{R}: 0,0 \mathrm{~L} \mathrm{ha}^{-1}, 0,5 \mathrm{~L} \mathrm{ha}^{-1}, 1 \mathrm{~L} \mathrm{ha}^{-1}$ e $2,0 \mathrm{~L}$ ha $^{-1}$, divididas em três aplicações nos estádios de perfilhamento, emborrachamento e floração. Foram feitas avaliações fisiológicas e filotécnicas como fluorescência da clorofila, taxa de transporte de elétrons, diâmetro, altura, massa seca, número de perfilhos e fitoxidade. A qualidade fisiológica das sementes foi avaliada pelos seguintes testes: germinação, primeira contagem, índice de velocidade de germinação, emergência, estande inicial. A cultivar BR18 produziu maior quantidade de perfilhos, massa seca, clorofilas A, B e total e de Fv/ Fm do que a cultivar BR254 com aplicação foliar de silício. A taxa de transporte de elétrons, fluorescência inicial e a fitotoxicidade forma influenciadas negativamente pelo aumento das doses de silício foliar para ambas as cultivares. A aplicação de silício foliar não interfere na qualidade das sementes de trigo, porém melhorou o desempenho de emergência, estande inicial e IVE da cultivar BR18.
\end{abstract}

Palavras chave: qualidade, silício foliar, triticum aestivum.

\section{FOLIAR APLICATION OF SILICON ON WHEAT PLANTS ASSOCIATED WITH PHYSIOLOGICAL QUALITY OF THE SEEDS}

\begin{abstract}
In the search for seeds and plants of high quality, the use of silicon can be interesting in agriculture, as it can increases productivity, regulates water loss, improves photosynthetic rate, increases stiffness of tissue structure, among others. Thus, the objective of this research was to verify the effect of foliar application of silicon on growth, physiology of wheat plants and the quality of wheat seeds produced. The experimental design was a randomized block with $2 \times 4$ factorial with 5 replicates, where the treatments were composed of two wheat cultivars (BR18 and BRS254) and four dosages of the commercial formulation Supa Silica of the brand Agrichem ${ }^{\circledR}: 0.0 \mathrm{~L} \mathrm{ha}^{-1}$ ), $0.5 \mathrm{~L} \mathrm{ha}^{-1}, 1 \mathrm{~L} \mathrm{ha}^{-1}$ and $2.0 \mathrm{~L} \mathrm{ha}^{-1}$, divided into three applications in tillering, rubber and flowering stages. Physiological and phytochemical evaluations were carried out, such as chlorophyll fluorescence, electron transport rate, diameter, height, dry mass, number of tillers and phytoex. The physiological quality of the seeds was evaluated by the following tests: germination, first count, germination speed index, emergence, initial stand. The cultivar BR18 produced a higher amount of tillers, dry mass, chlorophyll A, B and total and FV / FM than the cultivar BR254 with foliar application of silicon. The rate of electron transport, initial fluorescence and phytotoxicity were negatively influenced by the increase of foliar silicon doses for both cultivars. Leaf silicon application did not interfere with wheat seed quality, but it improved the emergency performance, initial stand and IVE of cultivar BR18.
\end{abstract}

Keywords: foliar silicon, quality, Triticum aestivum.

\footnotetext{
${ }^{1}$ Universidade Federal dos Vales do Jequitinhonha e Mucuri, Departamento de Agronomia, Diamantina, MG, Brasil

*Contato para correspondência: cintiamtfialho@yahoo.com.br
} 


\section{INTRODUÇÃO}

O trigo (Triticum aestivum L.) é uma planta anual, cultivada entre as estações do inverno e primavera, o seu grão é processado em farinha, a qual pode ser consumida na alimentação humana e animal (EMBRAPA TRIGO, 2013). De acordo com a FAO (2016), o trigo e o segundo cereal mais produzido no mundo, com uma produção mundial de 729,5 milhões de toneladas na safra de 2015. A produtividade média no Brasil atingiu na safra de 2014/20152.698 $\mathrm{kg} \mathrm{ha}^{-1}$, com uma estimativa de produção total de 7 milhões de toneladas (CONAB, 2015).

O trigo é uma espécie considerada acumuladora de silício ( $\mathrm{Si}$ ) devido ao processo ativo de absorção pelas raízes, atingindo teores médios de Si nas folhas acima de $10 \mathrm{~g} \mathrm{~kg}^{-1}$ de matéria seca (Oliveira, 2009). O silício é um elemento benéfico às plantas, podendo trazer incrementos na produtividade e sanidade (Sripanyakorn et al., 2005). A utilização do silício na agricultura é interessante quando o consideramos um anti-estressante natural. Estresses causados por temperaturas extremas, veranicos, metais pesados ou tóxicos, por exemplo, podem ter seus efeitos reduzidos com o seu uso deste. A fertilização com silício atua também aumentando a resistência a várias doenças fúngicas e algumas pragas (Savant et al., 1997).

O silício é um elemento não essencial e não tóxico para as plantas, podendo contribuir para o desempenho da cultura do trigo. Assim ele pode incrementar a produtividade; regular a perda de água; melhorar a taxa fotossintética; aumentar a rigidez da estrutura dos tecidos; reduzir os índices de acamamento; diminuir os danos causados pela geada; além de diminuir o efeito tóxico de ferro e manganês às raízes (Datnoff et al., 2007). A absorção e acumulação de silício na parte aérea do trigo é determinada, também, pela transpiração, crescimento (Duda et al., 2001) e disponibilidade do elemento no substrato. O aumento da temperatura aumenta o teor de silício nos tecidos do trigo (Su et al., 2002), já que aumenta a transpiração. Os depósitos de silício ocorrem nos tecidos estruturais, vasculares, de armazenamento e na epiderme, como constatado em plântulas de trigo. A silicificação das paredes das células da endoderme das raízes de trigo ocorre de maneira bastante rápida. Uma vez silicificados os sítios da endoderme radicular, a maior parte do silício é transportado para a parte aérea da planta (Sangster et al., 2001).
A semente de trigo é uma cariópside com tamanho entre 6 a $8 \mathrm{~mm}$ de comprimento e 3 a $4 \mathrm{~mm}$ de largura, ela é formada pelo endosperma e o embrião, os quais estão envoltos pelo pericarpo, a testa e a camada de aleurona. O endosperma representa $83 \%$ da semente e é formado por grânulos de amido, enquanto o embrião ocupa uma pequena porcentagem da cariópside, contendo as estruturas básicas para dar origem a uma nova planta (Setter \& Carlton, 2000). Oliveira (2009), trabalhando com arroz, verificou que a germinação das sementes produzidas não foi alterada com a aplicação das doses de silício e o vigor das sementes produzidas foi incrementado.

Apesar da pesquisa sobre os efeitos do Si no crescimento das plantas, muitas informações ainda são incipientes, principalmente quando se trata da correlação entre as características fisiológicas e de crescimento da planta e a qualidade das sementes. Dessa forma, objetivou-se com essa pesquisa verificar o efeito da aplicação foliar de silício no crescimento, na fisióloga de plantas de trigo e na qualidade de sementes produzidas.

\section{MATERIAL E MÉTODOS}

O experimento foi conduzido no Laboratório de Sementes e na casa de vegetação da Universidade Federal dos Vales do Jequitinhonha e Mucuri, localizado no município de Diamantina - MG.

O delineamento experimental adotado foi em blocos casualizados, em esquema fatorial $2 \times 4$ com 5 repetições, e os tratamentos foram compostos por duas cultivares de trigo, BRS-254 e BR-18, e quatro doses da formulação comercial Supa Sílica da marca Agrichem ${ }^{\circledR}$ : 0,0 Lha ${ }^{1}$ (Tratamento controle), 0,5 $\mathrm{Lha}^{-1}, 1,0 \mathrm{~L} \mathrm{ha}^{-1}$ e 2,0 L $\mathrm{ha}^{-1}$. Foi utilizada a dosagem recomendada para arroz $1,0 \mathrm{~L} \mathrm{ha}^{-1}$, meia dosagem e uma superdosagem, pois não há registros de dose recomendada para trigo. As aplicações de silício foram divididas em três períodos: nos estádios de perfilhamento, de emborrachamento e de floração.

As plantas de trigo foram cultivadas em vasos de $12 \mathrm{~L}$, onde foram semeadas 3 sementes por vaso, permanecendo, após o desbaste, as duas plantas emergidas mais precocemente.

Para adequação do substrato foi realizado a análise química e física do solo (Tabela 1). A adubação das plantas foi realizada de acordo com Souza \& Fronza 
(1999), respeitando o teor de nutrientes recomendado para o Triticum spp.

Foram aplicados o equivalente a $60 \mathrm{~kg} \mathrm{ha}^{-1} \mathrm{de}$ superfosfato simples, $50 \mathrm{~kg} \mathrm{ha}^{-1}$ de cloreto de potássio e $120 \mathrm{~kg} \mathrm{ha}^{-1}$ de sulfato de amônia. A adubação nitrogenada foi também realizada em cobertura aos 30 dias após a emergência da cultura, na dose de $30 \mathrm{~kg} \mathrm{ha}^{-1}$ de sulfato de amônio previamente dissolvido em água.

As duas cultivares de trigo foram semeadas na mesma época. As aplicações da solução de sílica foram aspergidas via foliar com borrifador manual na face adaxial até o ponto de escorrimento sem o uso de adjuvantes aos 25, 45 e 70 dias após a emergência nas fases de perfilhamento, emborrachamento e floração, respectivamente. Foram feitas visitas diária.

As variáveis da fluorescência da clorofila $a$ foram determinadas 75 dias após o plantio, com o fluorímetro portátil de luz modulada MINI-PAM (Walz, Germany), as pinças do aparelho foram colocadas no terço médio da primeira folha completamente expandida das plantas, avaliando a fluorescência inicial (Fo), fluorescência máxima $(\mathrm{Fm})$, a razão entre a fluorescência variável e fluorescência máxima (Fv/ Fm) e a taxa de transporte de elétrons (ETR - iMols elétrons $\mathrm{m}^{-2} \mathrm{~s}^{-1}$ ). As medições foram feitas após 30 minutos de adaptação ao escuro, no período noturno, com emissão de um pulso de luz saturante de $0,3 \mathrm{~s}$, sob frequência de $0,6 \mathrm{KHz}$. A avaliação dos teores de clorofila A, B e total foram realizadas com auxílio do clorofilômetro portátil Clorofilog Falker, na mesma folha onde foi avaliada a fluorescência, e os resultados foram expressos em índice de clorofila. Foram feitas sete leituras durante o ciclo da cultura, e calculou-se a média por planta para cada folha amostrada com o próprio medidor.

Avaliou-se também a intoxicação visual da cultura após a última aplicação da solução silicada 65 dias após o plantio. Os sintomas foram avaliados com uso de escala percentual de notas variando entre 0 (zero) e 100 (cem), onde 0 implica ausência de quaisquer injúrias e 100, a morte da planta

Foram avaliadas semanalmente variáveis do crescimento da planta, como diâmetro do colmo, altura, número de perfilhos. Diâmetro e altura foram medidos por paquímetro e régua respectivamente, e o número de perfilhos foi avaliado por contagem em unidades.

Aos 105 dias de cultivo do trigo foi desmontado o experimento, a parte aérea e a raiz foram separadas, sendo a parte aérea colocada em sacos de papel, secas em estufa com circulação forçada de ar, regulada à temperatura de $60^{\circ} \mathrm{C} \pm 2{ }^{\circ} \mathrm{C}$, até atingir peso constante (Krzyzanowski et al., 1999). Em seguida, as amostras foram pesadas em balança com precisão de 4 casas decimais, sendo os resultados expressos em g planta${ }^{1}$, determinando a massa seca das plantas.

Após 105 dias do cultivo do trigo com aplicação do silício, as sementes foram colhidas e foram realizadas as seguintes determinações e testes:

O grau de umidade foi determinado pelo método da estufa a $105^{\circ} \mathrm{C}$ por 24 horas, com quatro repetições para cada cultivar utilizando 4,5 gramas de sementes de trigo (BRASIL, 2009).

Teste de germinação - Foram utilizadas 200 sementes de trigo (quatro repetições de 50 sementes). As sementes foram semeadas sob três folhas de papel toalha previamente umedecidas com água destilada na proporção de 2,5 vezes o peso do papel. Os rolos foram colocados no germinador a uma temperatura de $20^{\circ} \mathrm{C}$, As contagens foram realizadas aos 4 e 8 dias após a semeadura. A apresentação dos resultados foi feita pela média aritmética das quatro repetições, em números porcentuais inteiros (BRASIL, 2009).

Tabela 1 - Resultado da análise física e química de um argisolo vermelho-amarelo

\begin{tabular}{|c|c|c|c|c|c|c|c|c|c|c|}
\hline \multicolumn{11}{|c|}{ Análise física $\left(\mathrm{dag} \mathrm{kg}^{-1}\right)^{1}$} \\
\hline Argila & Silte & Areia & & & & ssific & textur & & & \\
\hline 38 & 6 & 5 & \multicolumn{8}{|c|}{ Análise química ${ }^{1}$} \\
\hline $\begin{array}{c}\mathrm{pH} \\
\mathrm{H}_{2} \mathrm{O}\end{array}$ & \multicolumn{3}{|c|}{$\mathrm{mg} \mathrm{dm}^{-3}$} & $\mathrm{Al}^{3+}$ & $\begin{array}{c}\mathrm{Ca}^{2+} \\
\mathrm{cmol} \mathrm{dn}\end{array}$ & $\mathrm{Mg}^{2+}$ & CTC & $\begin{array}{l}\mathrm{V} \\
\%\end{array}$ & $\mathrm{~m}$ & $\begin{array}{c}\mathrm{MO} \\
\text { dag kg }^{-1}\end{array}$ \\
\hline 4,6 & 0,9 & 34 & 2,48 & 0,1 & 0,4 & 0,1 & 0,69 & 19 & 14 & 1,35 \\
\hline
\end{tabular}

Análises realizadas no Laboratório de Análise de Solos da Universidade Federal de Viçosa, Viçosa - MG. 
A partir da protrusão radicular das sementes foi determinado o índice de velocidade de germinação (IVG), calculado segundo Maguire (1962).

Teste de emergência- Foi conduzido em bandejas plásticas, com solo e areia em proporção 1:2, utilizandose quatro repetições de 50 sementes à temperatura ambiente. A partir do inicio da emergência foram feitas avaliações diárias, computando-se o estande inicial ao $4^{\circ}$ dia e a porcentagem de plântulas emergidas ao $8^{\circ}$ dia após a semeadura. O índice de velocidade de emergência (IVE) foi determinado segundo fórmula proposta por Maguire (1962).

$\mathrm{O}$ efeito dos tratamentos foi avaliado por meio da análise de variância pelo teste F ( $\mathrm{P} \mathrm{d}$ " 0,05$)$, onde foi realizado teste de Tukey a 5\% de probabilidade para cultivares e para as analises de qualidade de sementes e estudos de regressão para doses de silício e para a interação entre doses e cultivares. Os modelos de regressão escolhido foi mais adequado e significativo pela comparação dos coeficientes de determinação $\left(\mathrm{R}^{2}=\right.$ S.Q. Reg./S.Q. Trat). As análises foram realizadas com o programa computacional SISVAR (Ferreira, 2003) e para a confecção dos gráficos utilizou-se o programa SIGMAPLOT 10.0.

\section{RESULTADOS E DISCUSSÃO}

O grau de umidade das sementes foi de 14,80\% para a cultivar BR 18 e de $15,86 \%$ para a cultivar BRS 254 (Tabela 2), valor este próximo ao ideal para armazenamento de sementes de trigo que é de $13 \%$ (BRASIL, 2011).

Não houve interação entre os fatores, e sim o efeito isolado. Para as variáveis porcentagem de plântulas normais obtidas no teste de primeira contagem da germinação, germinação, emergência e índice de velocidade de emergência foi possível observar que as duas cultivares se distinguiram significativamente, tendo a cultivar BRS254 uma qualidade superior em relação a cultivar BR18. Pelo teste de IVG podemos perceber que a cultivar BR 18 possui qualidade superior a cultivar BRS254. O teste de estande inicial das duas cultivares não distinguiram significativamente (Tabela 2).

Com relação aos atributos de qualidade das sementes de trigo para as diferentes doses de silício (Tabela 3), observou-se que não houve diferenças significativas entre as cultivares BR18 e BRS254. Esses resultados corroboram com Segalin et al. (2013), que em experimento com doses de silício em trigo verificou que para estes parâmetros a aplicação foliar de silício não afetou a qualidade das sementes produzidas. Tavares et al. (2013) em estudo de adubação silicada via solo também concluíram que a adubação com silício não afetou a germinação das sementes produzidas. Para Rodrigues \& Datnoff(2005) o silício parece influenciar outras características, tais como supressão de agentes patogênicos, e a tolerância a estresse, dessa forma a germinação seria indiretamente afetada (Korndörfer \& Pereira, 2002).

Para as variáveis emergência, estande inicial e índice de velocidade de emergência a cultivar BR18 obteve bons resultados com aplicação foliar de silício enquanto para a cultivar BRS254 não foi possivel observar diferenças estatísticas significativas entre as dosagens. Na avaliação de emergência e índice de velocidade de emergência, a cultivar BR18 apresentou melhores resultados quando aplicado o silício, independente da dose em relação ao tratamento controle. $\mathrm{Na}$ avaliação de estande inicial do lote de sementes colhidas pós-aplicação de silício via foliar, também foi detectado o melhor desempenho para as dosagens 1 e $2 \mathrm{~L} /$ ha (Tabela 3 ).

De acordo com Rafi et al. (1997), a presença de silício pode resultar em aumento da capacidade biológica das sementes e plântulas em resistir às condições adversas do meio ambiente, incrementando então o vigor destas sementes. Resultados que corroboram com Harter \& Barros (2011), que trabalhando com aplicação de cálcio e silício em soja encontraram aumentos significativos no vigor quando comparados a testemunha.

Ao avaliar a quantidade de perfilhos por planta e massa seca foi encontrada uma diferença intergenotípica $(\mathrm{P}<0,05)$ entre as cultivares, onde a BR18 se destacou para as duas variáveis (Tabela 4). Essas diferenças na massa seca podem ter ocorrido devido ao maior perfilhamento do genótipo e também pela maior resposta a adubação foliar silicada, onde os mecanismos fisiológicos tem diferentes taxas de absorção, translocação e diferenças morfológicas no sistema radicular (Barbosa Filho et al., 1998) e foliar.

Para as variáveis fitotécnicas como quantidade de perfilhos e massa seca e para os teores de clorofila A, B, total, Fmax e FV/FM foram observadas diferenças intergenotípicas $(\mathrm{P}<0,05)$, observando maiores valores 
Tabela 2 - Resultados em porcentagem (\%) do grau de umidade - U; (\%) de plântulas normais na primeira contagem - PC; (\%) germinação - G; índice de velocidade de germinação - IVG; (\%) emergência - E; (\%) estande inicial - EI e índice de velocidade de emergência - IVE, obtidos em duas cultivares de sementes de trigo

\begin{tabular}{lccccccc}
\hline \multicolumn{7}{c}{ Testes } \\
\hline Cultivares & U (\%) & PC (\%) & G (\%) & IVG & E (\%) & EI (\%) & IVE \\
BR18 & $14,80 \mathrm{~b}$ & $93,5 \mathrm{~b}$ & $96 \mathrm{~b}$ & $25,42 \mathrm{a}$ & $96 \mathrm{~b}$ & $89 \mathrm{a}$ & $9,97 \mathrm{~b}$ \\
BRS254 & $15,86 \mathrm{a}$ & $100 \mathrm{a}$ & $100 \mathrm{a}$ & $25,29 \mathrm{~b}$ & $97 \mathrm{a}$ & $89 \mathrm{a}$ & $10,12 \mathrm{a}$ \\
CV \% & 2,37 & 1,84 & 0 & 4,59 & 2,2 & 5,26 & 18,74 \\
\hline
\end{tabular}

Médias seguidas da mesma letra na coluna não diferem entre si pelo teste $\mathrm{F}$ de probabilidade.

Tabela 3 - Resultados em porcentagem (\%) de germinação - G, plântulas normais na primeira contagem - PC, índice de velocidade de germinação - IVG, emergência - E, estande inicial - EI e índice de velocidade de emergência - IVE, obtidos em cultivares de trigo após aplicação foliar de silício

\begin{tabular}{|c|c|c|c|c|c|c|}
\hline \multirow{3}{*}{ Dose (L/ha) } & \multicolumn{6}{|c|}{ Testes } \\
\hline & \multicolumn{2}{|c|}{$\mathrm{G}(\%)$} & \multicolumn{2}{|c|}{ PC $(\%)$} & \multicolumn{2}{|c|}{ IVG } \\
\hline & BR18 & BRS254 & BR18 & BRS254 & BR18 & BRS254 \\
\hline 0 & $95 \mathrm{a}$ & $97 a$ & $95 a$ & $96 a$ & $27,26 \mathrm{a}$ & $29,14 \mathrm{a}$ \\
\hline 0,5 & $100 \mathrm{a}$ & $97 \mathrm{a}$ & $100 a$ & $97 \mathrm{a}$ & $28,67 \mathrm{a}$ & $28,65 \mathrm{a}$ \\
\hline 1,0 & $97 \mathrm{a}$ & $95 a$ & $97 \mathrm{a}$ & $95 a$ & $27,93 \mathrm{a}$ & $28,68 \mathrm{a}$ \\
\hline 2,0 & $98 \mathrm{a}$ & $97 a$ & $98 \mathrm{a}$ & $96 a$ & $28,67 \mathrm{a}$ & $29,37 \mathrm{a}$ \\
\hline \multirow[t]{2}{*}{$\mathrm{CV} \%$} & 2,28 & 2,46 & 2,28 & 3,04 & 4,07 & 2,96 \\
\hline & \multicolumn{6}{|c|}{ Testes } \\
\hline \multirow[t]{2}{*}{ Dose (L/ha) } & \multicolumn{2}{|c|}{ E $(\%)$} & \multicolumn{2}{|c|}{ EI (\%) } & \multicolumn{2}{|c|}{ IVE } \\
\hline & BR18 & BRS254 & BR18 & BRS254 & BR18 & BRS254 \\
\hline 0 & $79,5 b$ & $73,5 \mathrm{a}$ & $66 \mathrm{~b}$ & $72 \mathrm{a}$ & $11,19 b$ & $10,73 a$ \\
\hline 0,5 & $93,5 \mathrm{a}$ & $87 \mathrm{a}$ & $84,5 \mathrm{a}$ & $83,5 \mathrm{a}$ & $14,83 \mathrm{a}$ & $13,2 \mathrm{a}$ \\
\hline 1,0 & $90,5 a$ & $86 a$ & $83 \mathrm{ab}$ & $84 a$ & $13,99 a$ & $12,92 \mathrm{a}$ \\
\hline 2,0 & $88,5 \mathrm{a}$ & $80 \mathrm{a}$ & $90,5 \mathrm{a}$ & $70 \mathrm{a}$ & $15,36 \mathrm{a}$ & $10,41 \mathrm{a}$ \\
\hline $\mathrm{CV} \%$ & 3,9 & 10,94 & 9,74 & 13,21 & 7,38 & 15,04 \\
\hline
\end{tabular}

Médias seguidas de mesma letra minúscula na coluna não diferem significativamente entre si pelo teste de Tukey $5 \%$.

destas variáveis para o genótipo BR18 em relação ao genótipo BRS254 (Tabela 4).

Não se observou diferenças significativas $(\mathrm{P}<0,05)$ entre as doses de silício para o número de perfilhos, massa seca, clorofila A, B, total, Fmax e FV/FM no entanto de acordo com Silva et al. (2003) em outras espécies vegetais, a aplicação do silício promove aumento nas concentrações de clorofila por unidade foliar, significando que a planta pode tolerar níveis baixos e mais altos de luz disponível.

A fluorescência máxima (Fmax), definida como a intensidade máxima de emissão de fluorescência em que todos os centros de reação do FSII estão abertos (Baker \& Rosenqvist, 2004), apresentou diferença intergenotípicas significativa $(\mathrm{P}<0,05)$ destacando-se a cultivar BR18. Isso pode ser devido ao fato de ter em todo seu ciclo em média uma maior temperatura foliar $31,1^{\circ} \mathrm{C}$, do que a BRS254 que em média teve $30,7^{\circ} \mathrm{C}$, a temperatura foliar foi medida durante todo ciclo da cultura.

A razão entre a fluorescência variável e a máxima (Fv/Fm) expressa a eficiência quântica máxima de transporte de elétrons através do FSII, quando todos os centros de reação do FSII estão abertos (Krause \& Weis, 1991), que foi constatada diferença 
intergenotípicas significativa $(\mathrm{P}<0,05)$ destacando-se a cultivar BR18.

Ao avaliar a florescência inicial da clorofila (Fo) das plantas de trigo foram observadas diferenças intergenotípicas $(\mathrm{P}<0,05)$, com destaque para o genótipo BR1 8 (Tabela 4). Constatou-se também diferenças significativas $(\mathrm{P}<0,05)$ entre as doses de silício para esta variável (Figura 1A), observando um comportamento linear decrescente para a cultivar BR18 e um comportamento quadrático para BRS254, ou seja, para os dados avaliados, quanto maior a dose de silício aplicada, menor será a fluorescência inicial da clorofila para ambas as cultivares, podendo ser indicativo de danos estruturais nos centros de reação do fotossistema II ou comprometimento no transporte de energia de excitação dos complexos antena para os centros de reação (Bolhàr-Nordenkampf et al., 1989). O valor de
Fo é alterado por estresses do ambiente que causam alterações estruturais nos pigmentos fotossintéticos do PSII. Estresse por temperaturas infraótimas decresce significativamente os valores de Fo e o estresse por temperaturas supra-ótimas é caracterizado por incrementar drasticamente os valores de Fo (Ferreira et al., 2015).

Na taxa de transporte de elétrons houve interação entre os fatores, sendo significativo para a cultivar BRS254, enquanto que para a cultivar BR18 nenhum modelo foi significativo (Figura 1B). Foi gerada uma curva quadrática nota-se a diminuição da ETR com o aumento das doses de silício foliar absorvidas pela planta. A redução excessiva da taxa de transporte de elétrons e da relação $\mathrm{Fv} / \mathrm{Fm}$ pode ocasionar em um excesso de poder redutor, que pode culminar em danos fotoxidativos (Aucique-Perez et al., 2014).

Tabela 4 - Resultados em unidades de perfilhos, (g) de massa seca, em ( $\left.\mu \mathrm{g} \mathrm{cm}^{2}\right)$ de clorofila A, clorofila B e clorofila total (elétrons quantum ${ }^{-1}$ ) Fluorescência máxima de clorofila (Fmax) e Relação fluorescência máxima e fluorescência variável (FV/FM) obtidos em cultivares de trigo

\begin{tabular}{lccccccc}
\hline & \multicolumn{7}{c}{ Testes } \\
\cline { 2 - 7 } Cultivares & Perfilhos & Massa seca & Clorofila A & Clorofila B & Clorofila total & Fmax & Fv/Fm \\
\hline & (un) & $(\mathrm{g})$ & $\left(\mu \mathrm{g} \mathrm{cm}^{2}\right)$ & $\left(\mu \mathrm{g} \mathrm{cm}^{2}\right)$ & $\left(\mu \mathrm{g} \mathrm{cm}^{2}\right)$ & $($ elétrons quantum & \\
BR18 & $4 \mathrm{a}$ & $5,73 \mathrm{a}$ & $33,75 \mathrm{a}$ & $13,22 \mathrm{a}$ & $46,97 \mathrm{a}$ & $600,85 \mathrm{a}$ & $0,68 \mathrm{a}$ \\
BRS254 & $3 \mathrm{~b}$ & $3,40 \mathrm{~b}$ & $30,72 \mathrm{~b}$ & $12,19 \mathrm{~b}$ & $42,92 \mathrm{~b}$ & $341,40 \mathrm{~b}$ & $0,46 \mathrm{~b}$ \\
CV \% & 30,06 & 46,32 & 12,05 & 18,95 & 13,76 & 40,74 & 35,87 \\
\hline
\end{tabular}

Médias seguidas da mesma letra minúscula na mesma coluna não diferem entre si pelo teste $\mathrm{F}$ de probabilidade.
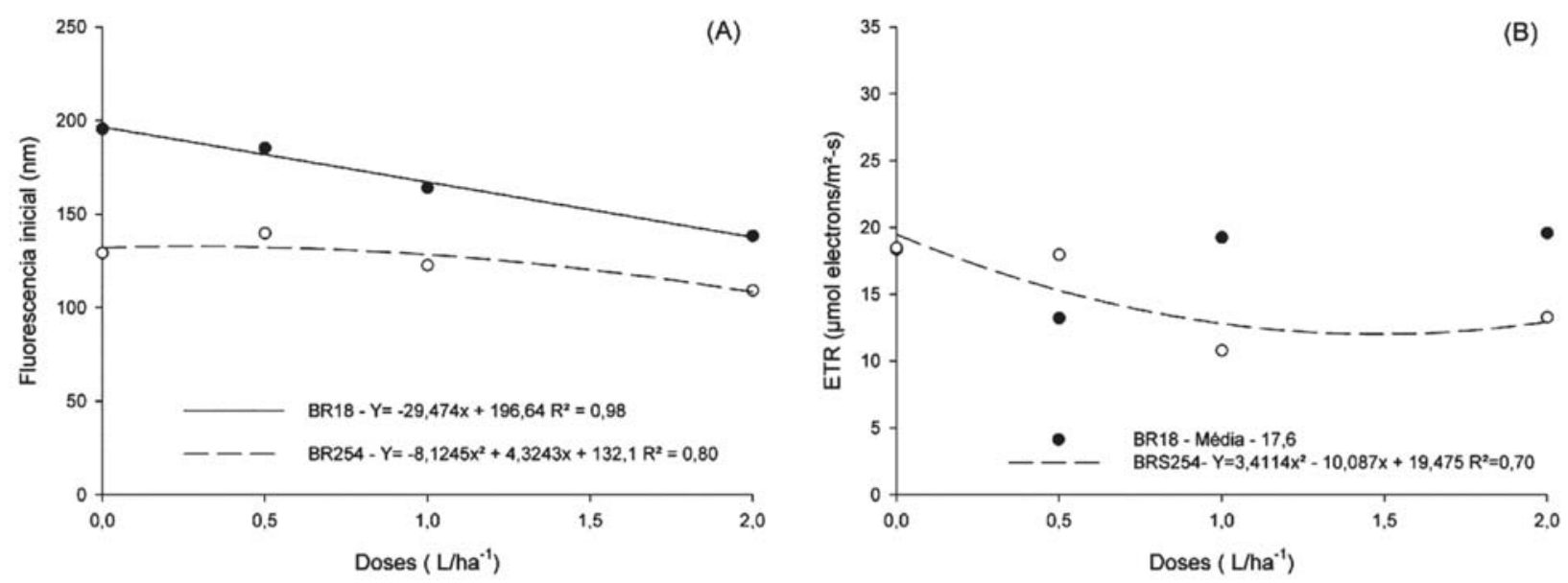

Figura 1 - (A) Fluorescência inicial da clorofila $a$; (B) Taxa aparente de transporte de elétrons (ETR); com diferentes doses de aplicação de silício foliar obtidas em duas cultivares de trigo. 


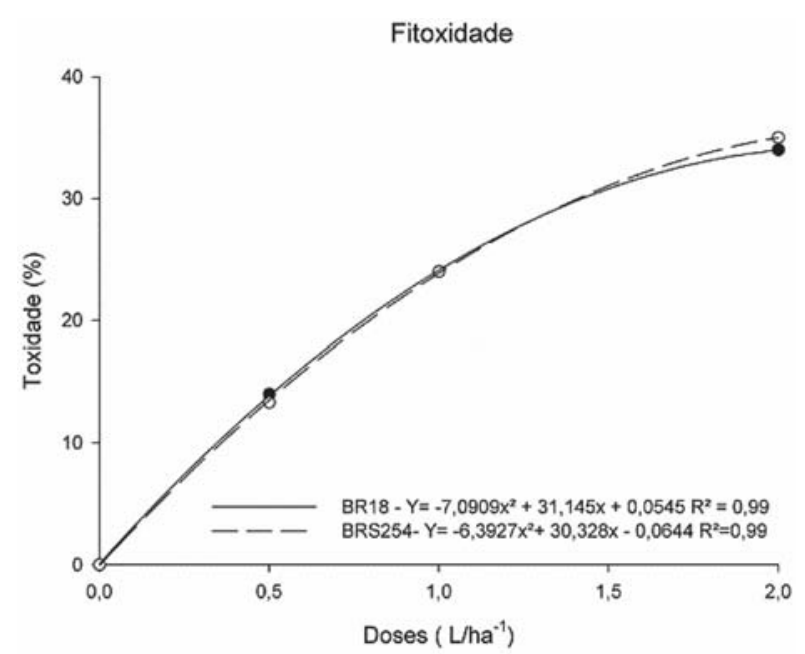

Figura 2 - Fitotoxicidade das plantas de trigo após a aplicação foliar de silício.

Ao avaliar a fitotoxicidade, observou-se o comportamento quadrático da curva com o aumento das doses para ambas cultivares (Figura 2), ou seja, quanto maior a dose aplicada via foliar, maior será a toxidez das plantas.

\section{CONCLUSÕES}

A aplicação de silício foliar não interfere na qualidade das sementes de trigo, porém melhorou o desempenho de emergência, estande inicial e IVE da cultivar BR18.

A cultivar BR18 produziu maior quantidade de perfilhos, massa seca, clorofila A, B e total, Fmax e Fv/Fm do que a cultivar BR254 com aplicação foliar de silício.

A taxa de transporte de elétrons, fluorescência inicial e a fitotoxicidade foram influenciadas negativamente pelo aumento das doses de silício foliar para ambas as cultivares.

\section{LITERATURACITADA}

AGrianuAL. Anuário da agricultura brasileira. São Paulo: FNP Consultoria e Comércio, 2008. 502p.

AUCIQUE-PEREZ, C.E.; RODRIGUES, F.A.; MOREIRA, F.M. et al. Leaf gas exchange and chlorophyll a fluorescence in wheat plants supplied with silicon and infected with Pyricularia oryzae. Phytophatology, v.104, p.143-149, 2014.
BAKER, N.R.; ROSENQVIST, E. Applications of chlorophyll fluorescence can improve crop production strategies: an examination of future possibilities. Journal Experimental of Botany, v.55, p.1607-1621, 2004.

BARBOSA FILHO, M.P.; SNYDER, G.H.; ELLIOTT, C.L. et al. Resposta do arroz de sequeiro à aplicação de silício. In: FERTBIO, 1998, Caxambu, MG. Anais. Lavras: UFLA; Sociedade Brasileira de Ciência do Solo; Sociedade Brasileira de Microbiologia, 1998. p.57.

BRASIL. Ministério da Agricultura, Pecuária e Abastecimento. Instrução Normativa n ${ }^{\circ} 38$, de 30 de novembro de 2010. Regulamento técnico do trigo. Diário Oficial [da] República Federativa do Brasil, Brasília, DF, n.29, p.2, 1 dez. 2011 . Seção 1.

BRASIL, Ministério de Agricultura. Regras para Análise de Sementes. Brasília, 2009 $395 p$.

BOLHÀR-NORDENKAMPH, H.R.; LONG, R.S.P.; BAKER, N.R. et al. Chlorophyll fluorescence as a probe of the photossinthetic competence of leaves in the field: a review of current instrumentation. Functional Ecology, v.3, p.497-514, 1989.

CONAB, 2015. Central de Informações Agropecuárias: safra de grãos 2014/ 2015. Disponível em <http://www.conab.gov.br/ OlalaCMS/uploads/arquivos/ 15_06_30_17_30_12_revista_junho_final_internet.pdf $>$. Acesso em: $17 \overline{\text { de }} \overline{\mathrm{ju}}$ lho de 2015 .

DATNOFF, L.E.; RODRIGUES, F.A.; SEEBOLD, K.W. Silicon and plant nutrition. In: DATNOFF, L.E.; ELMER, W.H.; HUBER, D.M. (Ed.).

Mineral nutrition and plant disease. 2007. p.233-246.

DUDA R.; GUTSER, R.; SCHMIDHALTER, U. Characterizing site specific differences in water availability. In: International plant nutrition colloquium, 2001. 14p.

EMBRAPA TRIGO. Cultura do trigo, Passo Fundo-RS, 22 ago. 2013. Online. Disponível em: $<$ http://www.cnpt.embrapa.br/culturas/trigo/ index.html>. Acessado em 22 ago. 2016. 
FAO, 2016. Disponível em: http://www.fao.org/ worldfoodsituation/csdb/en/. Acessado em 15 nov. 2016.

FERREIRA, D.F. Programa de análises estatísticas (statistical analysis sotware) e planejamento de experimentos SISVAR 5.0 (Build 67). Lavras: DEX/UFLA, 2003.

FERREIRA, E.A.; MATOS, C.C.; BARBOSA, E.A. et al. Respostas fisiológicas da mandioca à aplicação de herbicidas. Semina: Ciências Agrárias, v.36, n.2, p.645-656, 2015.

HARTER, F.S.; BARROS, A.C.S.A. Cálcio e silício na produção e qualidade de sementes de soja. Revista Brasileira de Sementes, v.33, n.1, p.054-060, 2011.

KORNDÖRFER, G.H.; PEREIRA, H. S. O silício e a tolerância ao estresse. Revista Citricultura Atual, v.4, n.26, p.12-13, 2002

KRAUSE, G.H.; WEIS, E. Chlorophyll fluorescence and photosynthesis: the basics. Annual

Review of Plant Physiology and Plant Molecular Biology, v.42, p.313-349, 1991.

KRZYZANOWSKI, C.F.; VIEIRA, R.D.; FRANÇA NETO; J.B. Associação Brasileira de Tecnologia de Sementes, Comitê de Vigor de Sementes. Londrina: ABRATES, 1999.

MAGUIRE, J.D. Speed of germination aid in selection and evaluation for emergence and vigour. Crop Science, v.2, p.176-177, 1962.

OLIVEIRA, L.A. Silício em plantas de feijão e arroz: absorção, transporte, redistribuição e tolerância ao cádmio. 2009. 157f. Tese (Doutorado) - Centro de energia nuclear na agricultura. Universidade de São Paulo, Piracicaba, 2009.

RODRIGUES, F.A.; DATNOFF, L.E. Silicon and rice disease management. Fitopatologia Brasileira, v.30, p.457-469, 2005.

RAFI, M.M.; EPSTEIN, E.; FALK. R.H. Silicon deprivation causes physical abnormalities in wheat (Triticum aestivum L.). Journal of Plant Physiology, v.151, p.497-501, 1997.
SANGSTER, A.G.; HODSON, J.; TUBB, H.J. Silicon deposition in higher plants. In: DATNOFF, L.E.; KORNDÖRFER, G.H.; SNYDER, G.H. (Ed.).

Silicon in agriculture. Amsterdam: Elsevier, 2001. p.85-113.

SAVANT, N.K.; SNYDER, G.H.; DATNOFF, L.E. Silicon management and sustainable rice production. Advances in Agronomy, v.58, p.151-199, 1997.

SETTER, T.L.; CARLTON, G. The structure and development of the cereal plant. In:

AUSTRALIAN GOVERNMENT. The Wheat Book, Principles and Practice. Camberra. 2000. 45p.

SEGALIN, S.R.; HUTH, C.; ROSA, T.A. et al. Foliar application of silicon and the effect on wheat seed yield and quality. Journal of Seed Science, v.35, n.1, p.86-91, 2013.

SILVA, U.C.; GALLI, M.A.; VAN DEN BROEK, H., et al. Eficiência de fungicidas orgânicos e silício em feijoeiro, para controle de oídio, mancha angular. Antracnose. Revista ecossistema, v.28, p.79-82, 2003.

SOUZA, M.A.; FRONZA, V. Trigo. In: RIBEIRO, A.C.; GUIMARÃES, P.T.G.; ALVAREZ, V.H.

Recomendações para o uso de corretivos e fertilizantes em Minas Gerais $-5^{\mathbf{a}}$ aproximação. Viçosa: Comissão de Fertilidade do Solo do Estado de Minas Gerais, 1999. p.332-339.

SU, R.Z.; LIU, Z.M.; LI, J. et al. Study on silica distribution of wheat straw surface. Scientia Silva e Sinicae, v.38, p.99-102, 2002.

SRIPANYAKORN, S.; JUGDAOHSINGH, R.; THOMPSON, R.P.H. et al. Dietary silicon and bone health. Nutrition Bulletin, v.30, p.222$230,2005$.

TAVARES, L.C.; MENCONÇA, A.O.; BRUNES, A.P. et al. Effect of silicon fertilization on the expression of isoenzymes, the germination and seed yield of wheat. Enciclopédia Biosfera, v.9, p.1214, 2013.

Recebido para publicação em 25/10/2017 e aprovado em 9/1/2018. 